\title{
Corrigendum
}

\section{Corrigendum to "Shewhart-Type Charts for Masked Data: A Strategy for Handling the Privacy Issue"}

\author{
Said Farooq Shah $\left(\mathbb{D},{ }^{1}\right.$ Zawar Hussain $\mathbb{D}^{\mathrm{D}},{ }^{2}$ Muhammad Riaz $\mathbb{D}^{\mathrm{D}},{ }^{3}$ and Salman Arif Cheema ${ }^{4}$ \\ ${ }^{1}$ Department of Statistics, University of Peshawar, Peshawar, Pakistan \\ ${ }^{2}$ Department of Social \& Allied Sciences, CUVS, Bahawalpur, Pakistan \\ ${ }^{3}$ Department of Mathematics and Statistics, King Fahd University of Petroleum and Minerals, Dhahran, Saudi Arabia \\ ${ }^{4}$ Department of Applied Sciences, National Textile University, Faisalabad, Pakistan
}

Correspondence should be addressed to Muhammad Riaz; riazm@kfupm.edu.sa

Received 10 April 2021; Accepted 10 April 2021; Published 24 April 2021

Copyright (C) 2021 Said Farooq Shah et al. This is an open access article distributed under the Creative Commons Attribution License, which permits unrestricted use, distribution, and reproduction in any medium, provided the original work is properly cited.

In the article titled "Shewhart-Type Charts for Masked Data: A Strategy for Handling the Privacy Issue" [1], Dr. Muhammad Riaz should be listed as the corresponding author to this article.

Additionally, the Acknowledgements section should read as follows.

"The author Muhammad Riaz would also like to acknowledge the support provided by the Deanship of Scientific Research (DSR) at King Fahd University of Petroleum and Minerals for funding this work through project SB191030."

\section{References}

[1] S. F. Shah, Z. Hussain, M. Riaz, and S. A. Cheema, "ShewhartType Charts for Masked Data: A Strategy for Handling the Privacy Issue," Mathematical Problems in Engineering, vol. 2020, Article ID 5104753, 11 pages, 2020. 